\title{
Vista technique and Platelet-Rich Fibrin Membrane for Treatment of Multiple Adjacent Gingival Recessions - 6 month follow-up.
}

\author{
Chenchev $\mathrm{Iv}^{1}$, Neichev $\mathrm{D}^{1}$, Vicheva $\mathrm{D}^{2}$, Atanasov $\mathrm{D}^{1}$, Noncheva $\mathrm{V}^{3}$ \\ ${ }^{I}$ Department of Oral Surgery, Faculty of Dental Medicine, Medical University - Plovdiv, Bulgaria \\ ${ }^{2}$ Department of Otorhinolaryngology, Medical Faculty, Medical University - Plovdiv, Bulgaria \\ ${ }^{3}$ Faculty Of Mathematics And Informatics, Plovdiv University "Paisii Hilendarski", Bulgaria
}

\begin{abstract}
Purpose: To do a clinical evaluation of the results of the treatment of multiple adjacent gingival recessions with VISTA technique (Vestibular Incision Subperiostal Tunnel Access) and platelet-rich fibrin membrane (PRF m).

Methods and materials: The study included 30 participants (19 women and 11 men) with multiple adjacent gingival recessions on both jaws of Miller's Class I and Class II. The surgical intervention was conducted using the VISTA technique in combination with platelet-rich fibrin membrane and the results were monitored for 6 months after the surgery. A total of 129 teeth with multiple adjacent gingival recessions were treated out of which 42 maxillary and 87 mandibular teeth.

Results: The value of the gingival recession depth $(G R D)$ on the $6^{\text {th }}$ month after the surgery was lowered from $2.94 \pm 0.54 \mathrm{~mm}$ to $0.40 \pm 0.30 \mathrm{~mm}$. Keratinized gingival width $(K G W)$ was increased from $1.20 \pm 0.85 \mathrm{~mm}$ to $1.77 \pm 0.65 \mathrm{~mm}$, while the probing pocket depth (PPD) was lowered from $2.27 \pm 0.34 \mathrm{~mm}$ to $2.08 \pm 0.24 \mathrm{~mm}$. The average value of the clinical attachment level (CAL) was lowered from $5.21 \pm 0.75 \mathrm{~mm}$ to $2.45 \pm 0.42 \mathrm{~mm}$. The gingival thickness $(G T H)$ was increased from $0.77 \pm 0.06 \mathrm{~mm}$ to $0.86 \pm 0.08 \mathrm{~mm}$. The mean percent of root coverage $(R C \%)$ at the end of the treatment with VISTA technique + PRF $m$ was $87.10 \pm 8.92 \%$.

Conclusions: Based on the results of our study we can get to the conclusion that the VISTA technique in combination with platelet-rich fibrin membrane can successfully be used as a treatment method of multiple gingival recessions of Miller's Class I and Class II.
\end{abstract}

Keywords: platelet-rich fibrin, gingival recession, VISTA technique, oral surgery

\section{Introduction}

Patients with gingival recessions often seek treatment because of impaired aesthetics, increased sensitivity and fear of losing teeth. In the cases of multiple adjacent gingival recessions, patients request that treatment is done in a single stage. The surgical treatment of such recessions requires a larger volume of donor connective tissue. This tissue is taken from the palate which greatly increases the difficulty and the probability of complications throughout the surgery and even afterwards ${ }^{[1]}$. In order to minimize these disadvantages, the method of GTR (guided tissue regeneration) ${ }^{[2]}$ with biodegradable and non-biodegradable membranes and biologically active substances such as acellular dermal matrix allograft $(\mathrm{ADM})^{[3]}$, enamel matrix derivate $(\mathrm{EMD})^{[4]}$, platelet-rich plasma (PRP) $)^{[5]}$, platelet-rich fibrin $(\mathrm{PRF})^{[6]}$ and more. The platelet-rich fibrin (PRF) was first introduced for the first time by Choukroun et al. in 2001 and is regarded as a second generation platelet concentrate. This autogenous biomaterial slowly releases growth factors which lasts for at least 7-28 days ${ }^{[7-11]}$. What is also important is that the resulting from the patient clot contains no chemical or biological additives while it has a solid structure and can easily be used to prepare strong, elastic fibrin membrane. Many publications with promising results appeared in the past few years about the treatment of gingival recessions

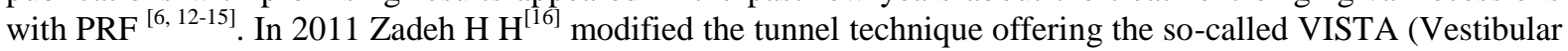
Incision subperiosteal Tunnel Access) technique for the treatment of multiple adjacent gingival recessions in the front part of the maxilla. The author makes use of subperiosteal tunnel flap in vertical vestibular incision in combination with collagen membrane soaked in $0.3 \mathrm{mg} / \mathrm{mL}$ rhPDGF-BB solution (recombinant human platelet derived growth factor BB). In 2014 Gupta $\mathrm{G}$ et al. ${ }^{[17]}$ and Chatterjee $\mathrm{A}$ et al. ${ }^{[18]}$ modify this technique by using PRF membrane (PRF m) instead of collagen membrane.

Purpose: To do a clinical evaluation of the results of the treatment of multiple adjacent gingival recessions with VISTA technique in combination with PRF membrane.

\section{Methods and materials}

The clinical study was conducted at the Department of Oral Surgery of Medical University - Plovdiv in the period of March 2014 to November 2015. A total of 30 patients (19 women and 11 men) participated in the 
Vista technique and Platelet-Rich Fibrin Membrane for Treatment of Multiple Adjacent Gingival...

study with multiple adjacent gingival recessions of Miller's Class I and Class II on both jaws. The patients were aged from 25 to 70 years with an average of 44,17 years. The surgical treatment was done using the VISTA technique with PRFm on 129 teeth with multiple adjacent gingival recessions. The affected and treated teeth were 42 maxillary and 87 mandibular. The results were monitored for six months postoperatively.

Inclusive criteria: Miller's recessions of Class I and Class II; Age of 18 and above; Patients without contraindications for surgical interventions; Good oral hygiene (plaque index < 20\%).

Exclusive criteria: Presence of severe systematic diseases or immunodeficiency; Intake of anticoagulants and antiaggregants; Pregnant with contraindications for surgical interventions; Data about allergies to medicaments used in the treatment process; Bad oral hygiene (plaque index > 20\%); Patients with removable or fixed dentures; Patients smoking more than 10 cigarettes a day or taking drugs.

Clinical measurements: With the aid of a periodontal probe and electric micrometer the follow parameters were measured in millimeters: gingival recession depth (GRD); keratinized gingival width (KGW); mean percent of root coverage ( $\mathrm{RC} \%$ ). The measuring was done prior to the surgery and on the $1^{\text {st }}, 3^{\text {rd }}$ and $6^{\text {th }}$ month afterward. Before the surgery and on the $6^{\text {th }}$ month after it were also monitored the values of probing pocket depth (PPD), clinical attachment level (CAL), creeping attachment (CA) and the gingival thickness (GTH). GTH was measured 2-3 mm below the gingival margin with a sterile endodontic instrument №15 with a sillicone stopper. After the application of local anesthesia the instrument was stuck at right angle all the way to the bone while the stopper moved tightly to the mucous membrane. The distance from the stopper to the tip of the instrument was measured with the micrometer accurate to two decimal places. ${ }^{[19]}$

Surgical treatment: The VISTA technique is essentially a modification of the double-layer tunneling technique that requires a single incision serving in the creation of the subperiosteal tunnel flap and an opening for the graft. Our modified technique is as follows: after the application of adequate local anesthesia, the affected by the recession teeth are cleaned, smoothed and polished with machinery tools. A vertical incision is made on the mucous membrane and the periosteum with a scalpel. The incision is $8-10 \mathrm{~mm}$ long, beginning from the mobile mucosa and reaching the apical end of the keratinized gingiva - Figure 1a. A small subperiosteal elevator is inserted through the incision and is used to free the subperiosteal tunnel flap. The flap includes the tissues of the mobile and immobile mucosa in the area of the affected teeth and about $1 \mathrm{~cm}$ distally and medially from them Figure 1b. A scalpel is used to make intrasulcular incisions covering up to a third of the papilla width medially and distally - Figure 1c.

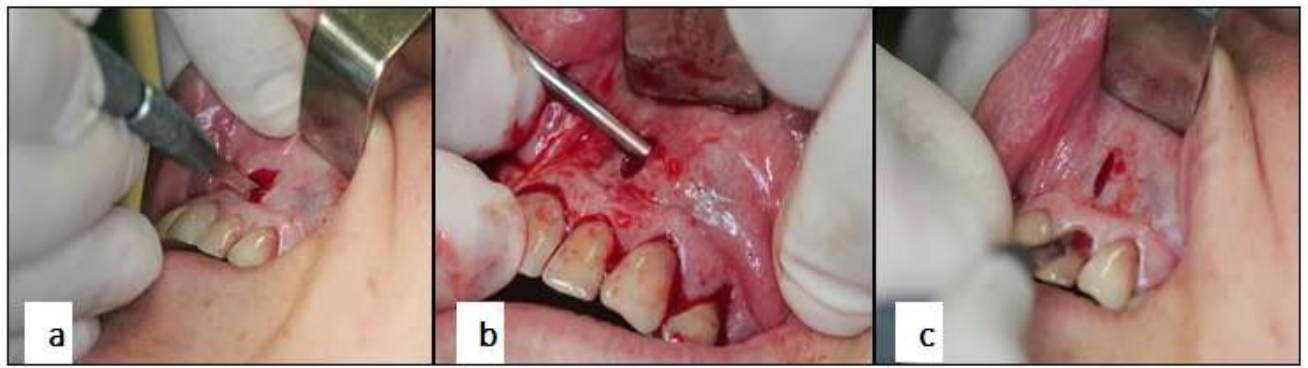

Figures \#1

Instruments for tunneling plastic are used through the vertical incision to free the mucosa and the periosteum around the affected by the gingival recessions teeth. This is continues at the base of the gingival papillae without affecting their entirety. The mucosa and the periosteum, below adjacent unaffected teeth laterally and medially from the affected ones, are freed using the method described above - Figure 2 a-c.

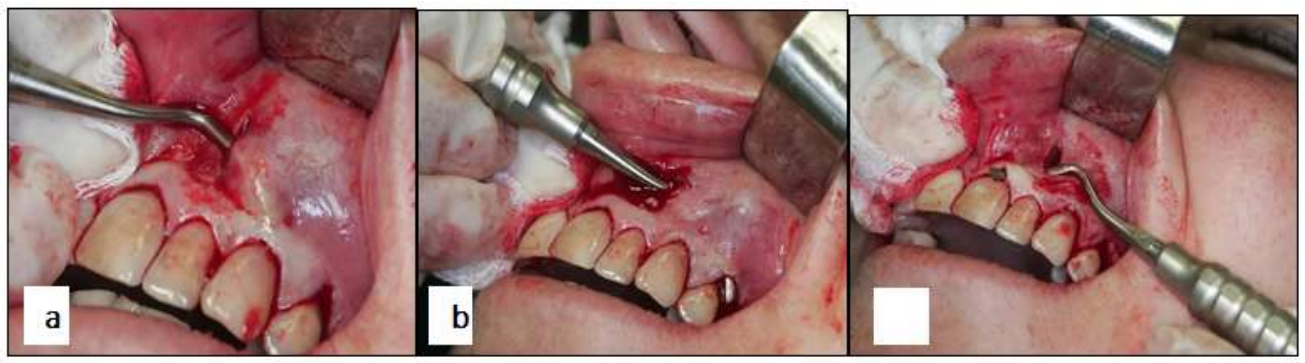

Figures \#2 
The previously prepared platelet-rich fibrin membranes are inserted through the entrance vertical incision - Figure 3 a, b. With a $1 / 2$ needle and biodegradable thread 0000 the vertical incision is stitched - Figure $3 \mathrm{c}$.

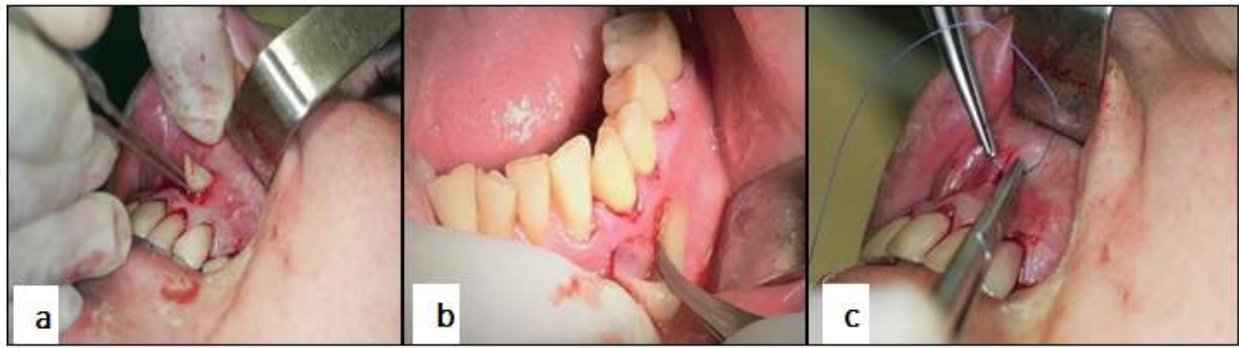

Figures \#3

Single horizontal sutures are made 2-3 millimeters below the gingival margin in the area of the affected teeth. They are knotted in a way that the knots can be fixed to the coronary surface of the corresponding tooth Figure 4a. The place where the knots (sutures) are fixed is defined in advance by the affected teeth and the occlusion type. The knots are fixed to the vestibular (fig. 4b) or lingual (fig. 4c) tooth surfaces with light curing liquid composite resin.

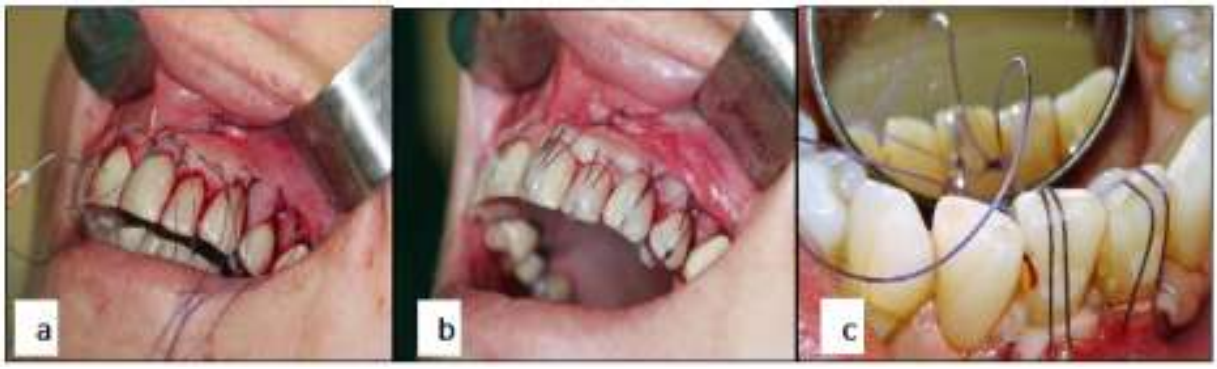

Figures \#4

We suggest that the incision, serving as an entrance point for the instruments necessary for the formation of the subperiosteal tunnel flap and the insertion of the platelet-rich fibrin membrane, is made in areas other than the frenulum of the maxilla or mandible. For this purpose we borrowed the idea from Chatterjce A et al. ${ }^{[18]}$ for the lingual fixation of the horizontal sutures with composite material. This allows for the fixation of the horizontal sutures to difficult or normally impossible vestibular areas - Figure 4c.

Preparation of the PRF membrane: The PRF membrane is prepared just before the surgery following the method of Choukroun et al. ${ }^{[7,8]}$ Depending on the necessity 2 to 4 tubes of blood are taken from each patient. The tubes are then immediately put into laboratory centrifuge PRF DUO (Processfor PRF ${ }^{\circledR}$ - France) and are centrifuged at $1500 \mathrm{rpm}$ for 8 minutes. The formation of the PRF $\mathrm{m}$ is made using our own method. This method is as follows: Two A- $\mathrm{PRF}^{\circledR}$ (Advanded - $\mathrm{RRF}^{\circledR}$ ) clots are dried out until two separate PRF membranes form - Figure 5a. These two membranes are then put on top of one another so that the parts bordering with the red zone are at the opposite ends - Figure $5 b$ This way the membranes are pressed with a metal plate and dried in A-PRF Box ${ }^{\circledR}$ - Figure 5c.
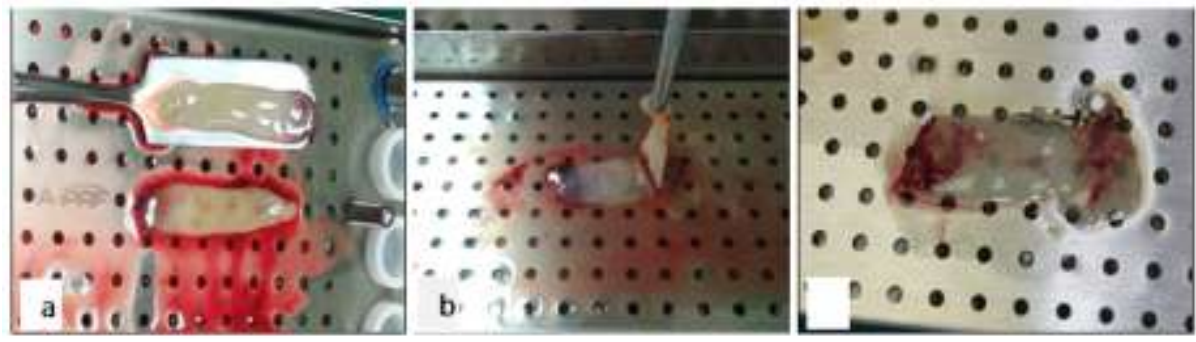

Figures \#5

Postoperative care: Postoperatively all patients were assigned therapy with NSAIDs for 3 days and mouth rinsing with $0,12 \%$ solution of chlorhexidine one minute three times a day for 14 days. The application of cold compresses in the surgery area and mushy-liquid diet for the first seven days were recommended. Checkup 
Vista technique and Platelet-Rich Fibrin Membrane for Treatment of Multiple Adjacent Gingival...

examination was done on the first day after the surgery, and the threads were removed on the $14^{\text {th }}$ day after. Patients were given instructions about the technique of personal hygiene and to avoid brushing the treated teeth for the next 14 days.

Statistical methods: The statistical analysis was done using the statistical analysis system R (v3.2.1) running on the operation system Windows ( 7 and XP). P $<0.05$ was chosen as the level of statistical significance at which the null hypothesis is rejected. For the presentation of our study we used a model know as Longitudinal Study. We also used the one-sample t-test of Student for dependent (paired) samples.

\section{Results}

The results of the study show improvement for all studied parameters with a statistical significance in comparison to the parameters measured before the treatment - Table \#1 and Table \#2. The mean percent of root coverage $(\mathrm{RC} \%)$ demonstrates a steady increase from the first to the sixth month postoperatively. Its average values for the first month were $85.98 \pm 9.92 \%, 86.98 \pm 9.20 \%$ for the third month and $87.10 \pm 8.92 \%$ for the sixth month. The values for the sixth month have a statistically significant value in comparison to those of the first month. There was, however, no statistical difference between the first and the third month - Table \#1.

Table 1. Results for clinical parameters before treatment and after treatment for 1,3, and 6 months

\begin{tabular}{|l|l|l|l|l|l|l|l|}
\hline Parameter & Baseline & 1 month & $P$ value & 3 month & $P$ value & 6 month & $P$ value \\
\hline GRD & $2.27 \pm 0.54$ & $0.44 \pm 0.34$ & $0.00^{*}$ & $0.41 \pm 0.31$ & $0.00^{*}$ & $0.40 \pm 0.30$ & $0.00^{*}$ \\
\hline KGW & $1.20 \pm 0.85$ & $1.76 \pm 0.65$ & $0.00^{*}$ & $1.77 \pm 0.65$ & $0.00^{*}$ & $1.77 \pm 0.66$ & $0.00^{*}$ \\
\hline RC \% & $\bullet$ & $85.98 \pm 9.92$ & $\bullet$ & $86.85 \pm 9.20$ & 0.120 & $87.10 \pm 8.92$ & $0.00^{*}()$ \\
\hline
\end{tabular}

Key of table \#1: GRD - gingival recession depth, KGW - keratinized gingival width, RC\% - mean percent of root coverage, * Statistically significant difference compared to the baseline, $†$ Statistically significant difference compared to the 1-th month

Table 2. Results for clinical parameters before treatment and after treatment for 6 months

\begin{tabular}{|l|l|l|l|}
\hline Parameter & Baseline & 6 month & $P$ value \\
\hline PPD & $2.27 \pm 0.34$ & $2.08 \pm 0.24$ & $0.000^{*}$ \\
\hline GTH & $0.77 \pm 0.06$ & $0.86 \pm 0.08$ & $0.002^{*}$ \\
\hline CAL & $5.21 \pm 0.75$ & $2.47 \pm 0.42$ & $0.000^{*}$ \\
\hline
\end{tabular}

Key of table \#2: PPD - probing pocket depth, CAL - clinical attachment level, GTH - gingival thickness, *Statistically significant difference compared to the baseline

\section{Discussion}

In order to minimize the surgical procedures and optimize the aesthetic results all adjacent gingival recessions should be treated in a single treatment stage. ${ }^{[20]}$ This can be achieved by making use of different surgical techniques, but most commonly different modifications of the tunneling technique are used. One important feature that makes the VISTA technique stand out of the rest is the difference in the approach used in the formation of the tunnel flap. In the VISTA technique there is a wide dissection of the soft tissues in order to eliminate possible pull. This allows for a maximal move of the tissues over the cementoenamel junction (CEJ) while the stitching technique effectively prevents possible apical movement of the marginal gingiva during the initial healing period. ${ }^{[16]}$ The elimination of the pull on the gingival tissues is essential in achieving good final results when treating gingival recessions. ${ }^{[21]}$ Preserving the entirety of the interdental papillae by avoiding their dissection ensures stability and fine local blood supply to the soft tissues. ${ }^{[16,22]}$ The stable fixation of the gingival tissues accounts for the lowering of their micro movement during the healing stage which is a great step ahead of the other techniques. ${ }^{[16,17,18,21]}$ In this study we use platelet-rich fibrin membrane in combination with the VISTA technique. The usage of this autogenous biological material eliminates completely the danger of adverse reactions to foreign (non-autogenous) materials. We used PRF membrane prepared in our own way from two A-PRF clots. The forming of the PRF membrane using our method aims to increase the concentration and the distribution of the platelets and leukocytes in the final membrane.

The results of this study show very good final covering of the recessions. The average gingival recession depth (GRD) before treatment was $2.94 \pm 0.54 \mathrm{~mm}$ which was reduced to $0.40 \pm 0.30 \mathrm{~mm}$ on the sixth month after - Table \#1. This result shows a statistically significant difference compared to the preoperative values of GRD. This data is similar to that of other study papers of different authors ${ }^{[16,17,18]}$ treating multiple adjacent gingival recessions with the VISTA technique. The values of the probing pocket depth (PPD) on the sixth month had decreased from $2.27 \pm 0.34 \mathrm{~mm}$ down to $2.08 \pm 0.24 \mathrm{~mm}$ - Table \#2. This decrease is statistically significant compared to the initial preoperative values. Alongside this the average values for the clinical attachment level (CAL) also show a reduction with statistically significant difference at the end of the postoperative period from $5.21 \pm 0.75 \mathrm{~mm}$ to $2.45 \pm 0.42 \mathrm{~mm}$ - Table \#2. This result is close to the result of a new study by Bherwani C. ${ }^{[23]}$ The author does a comparative evaluation of the results from the treatment of multiple 
Vista technique and Platelet-Rich Fibrin Membrane for Treatment of Multiple Adjacent Gingival...

gingival recessions with the tunneling technique combined with connective tissue graft (CTG) and modified technique of coronally position flap (Zucchelli's technique). Our results on the sixth month postoperatively show an increase of the gingival thickness $(\mathrm{GTH})$ with statistically significant values from $0.77 \pm 0.06 \mathrm{~mm}$ to $0.86 \pm 0.08 \mathrm{~mm}-$ Table \#2. This result correlates greatly with results reported by other authors. ${ }^{[23]}$ The keratinized gingival width (KGW) shows an increase from $1.198 \pm 0.85 \mathrm{~mm}$ up to $1.77 \pm 0.65 \mathrm{~mm}$ on the sixth month. The final values for KGW are statistically significant in comparison to the preoperative ones - Table \#1. All these results above are in conjunction with the results of other similar studies ${ }^{[16,17,18,22,24,25]}$ Our results, while different, are still to the ones reported by other authors ${ }^{[23,26]}$ when treating multiple gingival recessions with Zucchelli's technique without the use of connective tissue graft $(\mathrm{CTG})$ or collagen membrane. The mean percent of root coverage (RC\%) on the first and the third month after the surgery has a good result with a steady increase in its values - Table \#1. The results for RC \% on the sixth month after the treatment was $87.10 \pm 8.92 \%$. This value is slightly better than the one of the third month, but has no statistical significance. It, however, is statistically significant compared to the value of the first month. These resulting values are lower than the ones of other studies treating multiple gingival recessions with the VISTA technique. ${ }^{[16,17,18]}$ It should be noted that the results presented in these other studies are based on a small amount of single clinical cases. Our results are similar to those in the study of Khan SN et al. ${ }^{[27]}$ These authors performed a comparative treatment of multiple recessions with coronally advanced flap combined with platelet rich plasma (CAF + PRP) and coronally advanced flap alone. The results of our study when it comes to the per cent of root coverage are in contradiction with the results reported in Shetty SS's study. ${ }^{[28]}$ This author conducts a two-sided treatment of gingival recessions on a single patient with coronally advanced flap combined with platelet-rich fibrin membrane (CAF + PRFm) and coronally positioned flap combined with amnion membrane. The result is a $100 \%$ covering of the gingival recessions for both groups.

\section{Conclusions}

Based on the results from this clinical study we can conclude that the VISTA technique in combination with platelet-rich fibrin membrane can successfully be used as a treatment method for multiple gingival recessions of Miller's Class I and Class II. Additional clinical studies with a longer monitoring period and larger number of patients are need for better assessment of the VISTA technique with PRFm for the treatment of these recessions.

\section{Reference}

[1]. Dridi SM,Chousterman M,Danan M,Gaudy JF. Heamorrhagic risk when harvesting palatal connective tissue grafts: a reality? J Perio. 2008; 5(4):231-240

[2]. Tinti C, Vincenzi G.The treatment of gingival recession with guided tissue regeneration procedure by means of Gore-Tex membranes. ( La regenerazione guidata dei tessuti con Gore-Tex: nuove prospettive?) Quintessence Int. 1990;6: 465-468.(45-49).

[3]. Dodge JR, Henderson R, Greenwell H. Root coverage without a palatal donor site using an acellular dermal graft. Periodontal Insights 1998;5:5-8

[4]. Abbas F, Wennstrom J, Van der Weijden F, Schneiders T, Vander Velden U. Surgical treatment of gingival recessions using emdogain gel: clinical procedure and case reports. Int J Periodontics Restorative Dent 2003;23:607-13.

[5]. Petrungaro PS. Using platelet-rich plasma to accelerate softtissue maturation in esthetic periodontal surgery. Compend Contin Educ Dent 2001;22:729-32

[6]. Anilkumar K,Geetha A ,Umasudhakar et al.Platelet-rich fibrin:A novel root coverage approach.Journal of Indian Society of Periodontology 2009; 13 (1), 50-54.

[7]. Choukroun J, Adda F, Schoeffer C, Vervelle A. PRF: an opportunityin perio-implantology (in French). Implantodontie 2001; 42:5562.

[8]. 14.Dohan DM, Choukroun J, Diss A, et al. Platelet-rich fibrin (PRF):a second-generation platelet concentrate: Part I. Technologicalconcepts and evolution. Oral Surg Oral Med Oral Pathol Oral Radiol Endod 2006;101:37-44.

[9]. 15.Dohan DM, Choukroun J, Diss A, Dohan SL, Dohan AJ, Mouhyi J,

Gogly B. Platelet-rich fibrin (PRF): a second-generation platelet concentrate. Part III: leucocyte activation: a new feature for platelet concentrates? Oral Surg Oral Med Oral Pathol Oral Radiol Endod 2006;101:51-5.

[10]. Dohan Ehrenfest DM, Rasmusson L, Albrektsson T. Classification

of platelet concentrates: from pure platelet-rich plasma (PPRP) to leucocyte- and platelet-rich fibrin (L-PRF). Trends Biotechnol 2009;27:158-67.

[11]. Dohan Ehrenfest DM, de Peppo GM, Doglioli P, Sammartino G.

Slow release of growth factors and thrombospondin-1 in Choukroun's platelet-rich fibrin (PRF): a gold standard to achieve for all surgical platelet concentrates technologies.

Growth Factors 2009;27:63-9.

[12]. Aleksić Z, Janković S, Dimitrijević B, Divnić-Resnik T, Milinković I, Leković V. The use of platelet-rich fibrin membrane in gingival recession treatment. Srp Arh Celok Lek. 2010 Jan-Feb;138(1-2):11-8.

[13]. Del Corso M, Sammartino G, Dohan Ehrenfest DM. Del Corso M, Sammartino G, Dohan Ehrenfest DM. Clinical evaluation of a modified coronally advanced flap alone or in combination with a platelet-rich fibrin membrane for the treatment of adjacent multiple gingival recessions: a 6-month study. J Periodontol. 2009 Nov;80(11):1694-7

[14]. Jankovic S, Aleksic Z, Milinkovic I, Dimitrijevic B. The coronally advanced flap in combination with platelet-rich fibrin (PRF) and enamel matrix derivative in the treatment of gingival recession: a comparative study. Eur J Esthet Dent. 2010 Autumn;5(3):260-73.

[15]. Uraz A, Sezgin Y et al.Comparative evaluation of platelet-rich fibrin membrane and connective tissue graft in the treatment of multiple adjacent recession defects: A clinical study. Journal of Dental Sciences 2013; 10(1):35-46. 
[16]. Zadeh H. Minimal invasive treatment of maxillary anterior gingival recession defects by vestibular incision and subperiostal tunnel access and platelet-derived growth factor BB. The Int. J of Periodontics and Restorative Dentistry. 2011;31:653-660.

[17]. Gupta G. et al. Platelet-rich fibrin (PRF) Reinforced Vestibular Incision Subperiostal Tunel Access (VISTA) technique for recession coverage. Clinical Advences in Periodontics; 2014; 7:1-13.

[18]. Chatterjee A et al. Treatment of multiple gingival recession with VISTA technique: A case series. Journal of Indian Society of Periodontology. 2015;19(2),232-235.

[19]. Paolantonio M. Treatment of gingival recessions by combined periodontal regenerative technique, guided tissue regeneration, and subpedicle connective tissue graft. A comparative clinical study. J Periodontol 2002; 73:53-62.

[20]. Zucchelli G, De Sanctis M. Treatment of multiple recession-type defects in patients with esthetic demands. J Periodon- tol 2000; 71:1506-1514.

[21]. Pini-Prato GP, Pagliaro U, Baldi C, Nieri M, Saletta D, Cairo F, Cortellini P. Coronally advanced flap procedure for root coverage. Flap with tension versus without tension: arandomized controlled study. Journal of Periodontology 2000; 71: 188-201.

[22]. Zabalegui I, Sicilia A, Cambra J, Gil J, Sanz M. Treatment of multiple adjacent gingival recessions with the tunnel subepithelial connective tissue graft: a clinical report. Int J Periodontics Restorative Dent 1999; 19(2): 199-206.

[23]. Bherwani C, Kulloli A et al. Zucchelli`s technique or tunnel technique with subepithelial connective tissue graft for treatment of multiple gingival recessions. J of Int Acad of Periodontology 2014;16:1-9.

[24]. Girouard Marie-Eve. Root coverage comparing acellular dermal matrix to connective tissue graft using the coronally advanced tunnel technique. Canada, Qb, Montreal 2011; 45-50.

[25]. Papageorgakopoulos $\mathrm{G}$ et al. Root coverage using an acellular dermal matrix and comparing a coronally positioned tunnel to a coronally positioned flap approach. J Periodontol 2008; 79(6): $1022-1030$.

[26]. Pini-Prato GP, Cairo F et al. Coronally advanced flap versus connective tissue graft in the treatment of multiple gingival recessions: A split-mouth study with 5-year follow -up. J Periodontol. 2010; 37:644-50.

[27]. Khan $\mathrm{SN}$ et al. Clinical evaluation of a coronally advenced flap alone and in combination with platelet - rich plasma for the teatment of multiple gingival recessions. Indian J of Dentistry 2012; 3(1):33-36.

[28]. Shetty SS,Chatterjee A,Bose S. Bilateral multiple recession coverage with platelet-rich fibrin in comparison with amniotic membrane.J of Indian Society of Periodontology. 2014;18(1):102-106. 